\title{
DETERMINANTE ANTIRASISTIČNEGA IZOBRAŽEVANJA
}

\section{POVZETEK}

Vnovični vzpon fašizma v podobi »alt-desnice "kaže, da se liberalno antirasistično izobraževanje in propagiranje večkulturne družbe nista pokazali za posebej uspešni, navkljub velikim finančnim vložkom in institucionalnim prizadevanjem. Borni rezultati so posledica konceptualne redukcije rasizma na psihološko raven, na kognitivni spodrsljaj, ki ga ugotavljamo pri predsodkih, in na pomanjkljivo poznavanje, kar vse naj bi premagovali s primernim izobraževanjem in spoznavanjem drugih kultur. Nepoučenost o drugih kulturah pa je zgolj ena od determinant širše mrě̌e rasizma, pri katerem gre v temelju za vzpostavljanje avtoritarne hierarhije z namenom izkoriščanja in zlorabe, brez katerih moderni ekonomski in politični sistem ne more obstajati. Sodobni rasizem postkolonialne dobe v razmerah kulturne in ekonomske globalizacije, pa tudi novih oblik komunikacije, ima vrsto novih značilnosti, ki zahtevajo drugačne pristope k antirasizmu. Ker ne gre zgolj za izobraževalni projekt in ker je v sodobni šoli znanje praviloma omejeno na instrumentalni vidik, zahteva premagovanje rasizma tudi ponovni premislek neuspeha doseganja izobraževalnih ciljev in temu ustrezne spremembe. Te spremembe zadevajo predvsem preseganje neoliberalizma, dekolonizacijo razvitih dežel in vključitev epistemologij Juga.

Ključne besede: antirasizem, politična filozofija, izobraževanje, epistemologija Juga, postkolonializem, nova družbena gibanja

\section{THE DETERMINANTS OF ANTIRACIST EDUCATION - ABSTRACT}

The resurrection of fascism in the form of the alt-right demonstrates that liberal antiracist education and the propagation of a multicultural society were not particularly successful despite large financial input and institutional efforts. The meagre results are the consequence of the conceptual reduction of racism to the psychological level, a cognitive lapse, which can be observed in prejudice, or of lack of knowledge, all of which supposedly could be overcome with proper education and getting to know different cultures. But ignorance about other cultures is just one of the determinants in the wider web of racism, at its core concerned with establishing an authoritarian hierarchy with the aims of exploitation and abuse, without which the modern economic and political systems could not exist. Contemporary racism of the postcolonial era of cultural and economic globalization, and utilizing modern methods of communication, has all kinds of new features, which require different approaches to antiracism. Because it is not solely an educational project, and because contemporary schooling usually reduces knowledge to its instrumental aspect, overcoming racism also urgently requires the reconsideration of failed educational

Doc.dr. Darij Zadnikar, Pedagoška fakulteta Univerzev Ljubljani, darij.zadnikar@pef.uni-lj.si 
objectives and corresponding changes. These changes concern the overcoming of neoliberalism, the decolonization of developed countries and inclusion of the epistemologies of the South.

Keywords: antiracism, political philosophy, education, epistemologies of the South, postcolonialism, new social movements

Napisano v spomin na 43 študentov vaškega učiteljišča v mehiški Ayotzinapi, ki so bili 26. septembra 2014 aretirani ob protestih proti privatizaciji šolstva.

Od takrat se je izgubila vsaka sled za njimi.

\section{OD KVALITATIVNE HIERARHIJE DO HIERARHIČNEGA KONTINUUMA}

$\mathrm{S}$ stališča politične filozofije ni upravičeno trditi, da smo v zadnjem času, zlasti pa v letu 2016, bili priče renesansi in vzponu rasizma. Rasizem je, vsaj v svoji formni določitvi, konstitutiven del moderne družbe, ki mora imeti na voljo mehanizme, da se načelna enakost in enakopravnost praviloma sprevržeta $\mathrm{v}$ dejansko neenakost, ki brez težav sobiva $\mathrm{z}$ najbolj sprevrženimi oblikami družbenih zlorab in izkoriščanja.

Predmoderna, srednjeveška Evropa še ni poznala kvantitativne primerljivosti vsega in vseh, tako kot je to pri sodobnih tržnih razmerjih. Predmoderni evropski um je temeljil na katalogiziranju kvalitet, ki jim je določal povsem ločene pristojnosti. Tako npr. med stanovi nista bili možni nikakršna mobilnost in primerljivost, kar je izravnala šele smrt, a tudi ta je premešala vloge le zato, da bi duše premestila v nove povsem ločene svetove. Nekakšna kvalitativna primerljivost, ki ne ustreza današnji vseprisotni kvantitativni vrednostni (največkrat finančni) cenitvi, je temeljila na neumrljivi duši, ki jo je bilo treba katalogizirati ob koncu časa.

Začetek kolonialne ekspanzije, ki je določujoč za moderno, zlasti okupacija Amerik in tamkajšnji genocid staroselcev, je pripeljal do zasužnjevanja in transporta milijonov Afričanov in Afričank na drugo stran Atlantika. Neizmerno trpljenje in najgrozljivejše izkoriščanje Indijancev in Afričanov sta sprožili odpore in upore, pa tudi krščanske dvome med peščico pripadnikov kolonizatorske elite. Podobno, kot je bila nevprašljiva popolna podrejenost domačih živali, se je zasužnjevanje lahko spodbijalo le tako, da se je v Afričanih ali Indijancih odkrila neanimalna duša, primerna za krščansko zveličanje. ${ }^{1}$ To »odkritje « naj bi dokazovalo neprimernost njihovega zasužnjevanja. Marsikdo v tej dobrohotnosti kolonizatorjev vidi danes začetek koncepta univerzalnih človekovih pravic, a dejansko so bili množični upori sužnjev in staroselcev ter emancipacijska prizadevanja posameznikov tisti, ki so (in bodo) vodili k osvobajanju. Res pa je tudi, da ni bila ne Afričanom

1 Razprava v Valladolidu (1550-1551), kjer se je izkazal Bartolomé de las Casas, je bilo prvo takšno preizpraševanje pravic koloniziranih ljudstev. 
ne Indijancem priznana njihova duša, ampak so jih iz animalnega stanja »povzdignili« tako, da jim je bila zlepa ali zgrda podeljena krščanska duša. Ustreznost krščanske duše pa je v tem, da še posebej dobro uspeva, oziroma trpi, v brezdušnih razmerah. Kljub vsemu je Latinska Amerika proizvedla mestizaje, ${ }^{2}$ mešanico odtenkov polti, kultur, glasbe in kulinarike, temperamentov in trmastih praks odpora, kakršno težko najdemo kjerkoli drugje na našem planetu, tako da, če že hočemo iskati kulturno univerzalnost, je ne moremo ne v antičnih Atenah ne v modernem Londonu, temveč prav v tovrstnem mestizaje med seboj prežemajočih se in odprtih raznovrstnih kultur. ${ }^{3}$ Četudi suženjstvo ni bilo takoj odpravljeno in čeprav smo imeli prvo republiko uporniških sužnjev na Haitiju od leta 1805, abolicijo v ZDA pa šele po državljanski vojni 1861-1865, se je to ohranilo vse do današnjih dni, kot pri peonih na ruralni »periferiji« ali pa v globaliziranih »švicfabrikah« (maquilladores, sweatshops), pa tudi pri izkoriščanju migrantov, trgovini z ljudmi itn.

Ko se je skozi čas evropska krščanska duša, čakajoča na končno sodbo, prelevila v pravno subjektivnost, ki ji je zagotovljen enakopraven dostop do pravosodja, se je postopoma odpravila kategorialna kvalitativna razdelitev hierarhij in odprla drugačna možnost hierarhičnega razvrščanja. Kot rečeno, zdaj velja načelna enakost, ki šele omogoča vsesplošno kvantifikacijo in primerljivost, ki doseže svoj ideal v blagovno-finančnih trgih. Stanovski sistem tega ni rabil, saj so bile cene, kakovost, postopki in rituali družbenega umeščanja vnaprej določeni in zacementirani. Kvantitativno hierarhijo vrednosti lahko določi šele moderni ekonomski sistem prek abstraktne primerljivosti vsega in vseh z vsem in vsakim. V tem smislu sta lastnik produkcijskih sredstev ali rentnik ter lastnik delovne zmožnosti na istem: sta lastnika, ki morata skrbeti za dobičkonosnost lastninskega vložka. Ta »resnica« predpostavlja epistemološko slepo pego, ki jo zaznamo ob znameniti izjavi Margaret Thatcher, da družba ne obstaja, temveč obstajajo zgolj posamezniki. Da, a le kot posamezniki, ki zasedajo različne pozicije v družbi, ki jim omogočajo različne moči nad drugimi posamezniki. Od tega pa neoliberalci navadno abstrahirajo in se obnašajo kot utopični komunisti, le da je pri njih komuno zamenjal ideal univerzalnega trga. ${ }^{4}$ Dejstvo namreč je, da takšen idealen samoregulacijski trg nikoli nikjer ni obstajal in so ga zmeraj »uresničevali« z vojaško močjo (kolonializem, imperializem), vsiljevanjem monopolov (OECD), korupcijo (politični razred, davčne oaze), ideološko propagando (nacionalizem, rasizem, fašizem) in kulturo osamelosti (potrošništvo, egoistični individualizem, kulturna industrija, edukacijski sistemi).

\section{KONSTRUKT DRUGEGA OHRANIA HIERARHIČNI KONTINUUM}

Kakorkoli že, togo predmoderno hierarhijo je zamenjala moderna »pretočna « hierarhija. Če te je poprej rojstvo hierarhično umestilo do smrti, poznejša sodba pa za vekomaj, smo

2 Izraz je rabljen v pomenu kanibalizma pri Viveirosu de Castru (2014), kjer se odpravljeni kanibalizem staroselcev preoblikuje $\mathrm{v}$ prebavo kolonizatorske kulture in ustvarjanje fleksibilnih subjektivitet.

3 Ta proces v Latinski Ameriki ni enovit in je poln protislovij, ki segajo v naš čas.

4 V obeh primerih gre za idealizirano končno stanje, ki ni nič drugega kot sekularizacija krščanske končne sodbe, ko se božje kraljestvo spusti tudi »na zemljo«. 
zdaj umeščeni v sistem permanentne »evalvacije«. Kategorialna hierarhija in moderni hierarhični kontinuum predpostavljata različni subjektivnosti: medtem ko se mora ena sprijazniti z dodeljenim mestom in ji ne sme pasti na pamet, da bi segala onkraj omejitev lastnega stanu, pa je moderna subjektivnost zaznamovana s kontinuiranim konkurenčnim prerivanjem na družbeni lestvici ne/uspeha. Hierarhični kontinuum ne/moči in nad/moči je fleksibilen, mobilen in negotov, kar je tudi vgrajeno $\mathrm{v}$ vrednotni sistem meščanskega liberalizma. Revolucionarni obrat od fevdalizma hierarhije ni ukinil, temveč jo je transformiral tako, da jo je odprl za svoboden boj vseh proti vsem.

Hierarhija (gospostvo) temelji na podrejanju in nadrejanju, oziroma na tem, da se posameznikom in skupinam odvzame možnost, da nadzirajo in sooblikujejo okoliščine svojega življenja. Gre za stanje navzdol stopnjujoče se ogroženosti, ki izhaja iz pomanjkanja avtonomije oziroma podrejenosti osebni ali strukturni nadmoči. Robert Sapolsky, stanfordski nevroendokrinolog in primatolog, je dokazal tesno povezavo med stresom, ki je posledica zasedanja nižje pozicije $\mathrm{v}$ hierarhiji, in resno obolelostjo med posamezniki (Sapolsky, 2008). Temu so pritrdile tudi raziskave, v katere je bilo vključenih desettisoče britanskih javnih uslužbencev (Whitehall I in II). ${ }^{5}$ Sodobna družba konkurence oziroma hierarhičnega kontinuuma dobesedno mori, prav tako kot številne vojne, ki jih povzroča taisti sistem. Zdi se, da je tudi moderna našla svojo črno smrt; medtem ko je bila to za srednjeveški svet neogibna božja kazen, smo danes pač prepuščeni neki drugi nevidni roki.

Ko Margaret Thatcher izjavi, da družba ne obstaja več, ima v mislih absolutno vlogo hierarhičnega kontinuuma, na katerem nastopamo kot tekmujoči individuumi. Ta kontinuum je mogoče sabotirati le tako, da premagamo medsebojno izoliranost in rekuperiramo skupnosti, ki jih je kapitalizem razkrojil. Z drugimi besedami, solidarnost je sabotaža tržnega kontinuuma. Ta solidarnost se $\mathrm{z}$ velikimi težavami lahko izgradi na horizontali najnižjih slojev, med katerimi je konkurenca (predvsem na trgu dela) najhujša. Bolj ko gremo po hierarhičnem kontinuumu navzdol, težje je vzpostaviti to horizontalno solidarnost, ki ji potem - nikakor ne v sociološkem pomenu, ker gre za skupnost odpora - pravimo družbeni razred. Ker pa je ta solidarnost sabotaža podreditve sistemu gospostva, gre zato tudi za razredni boj. ${ }^{6}$ Danes se vedno bolj zavedamo, da razred ni edina ali pa primarna oblika odpora, saj se vzpostavlja množica singularnih izhodišč skupnosti odpora (feminizem, ekologija, antirasizem, LGBT itn.) in njihovih potencialnih medsebojnih zavezništev.

A »naravno« stanje te moderne podstati je vendarle Hobbsovski bellum omnium contra omnes, kjer je izjemno težko vzpostaviti polje solidarnosti, ki bi jo, povsem v nasprotju z liberalci in običajno rabo v govorici, imenoval politika.

Ko Sapolsky kot primatolog proučuje krdelo pavijanov v Keniji, njihovo togo hierarhijo in občasne nasilne izbruhe alfa samcev nad podrejenimi, poroča tudi o tem, kako se

5 Viri za Whitehall I in II navedeni na http://unhealthywork.org/classic-studies/the-whitehall-study.

6 Zato sta zmaga Thatcherjeve nad stavkajočimi rudarji (1984-1985) in zlom delavskega gibanja (sindikatov) s pomeščanjenjem laburistov mejnika neoliberalne in neokonzervativne revolucije, ki določata današnji zahodni svet individualizirane etike egoizma in potrošništva. 
frustracija v obliki nasilja hitro razširi navzdol po lestvici, vse do tega, da samice na koncu trpinčijo svoje mladiče. Raziskovalec seveda zadeve proučuje v svojem naravoslovnem znanstvenem okviru merjenja stresnih hormonov. ${ }^{7}$ Ker vemo, da je psihologija množic preprostejša od psihologije posameznika, nam je doumljivo pogosto razreševanje frustracij z znašanjem nad podrejenimi in nemočnimi. Po tej logiki je seveda ta mehanizem močnejši tam, kjer je solidarnost manjša oziroma sta medsebojna konkurenca in frustracija (stres) večji. Zadeva se zaplete na družbenem dnu, kjer naj bi ljudje životarili zgolj od svojega dela za druge, saj ni nobenega pod njimi, nad katerimi bi izživljali svoje frustracije. Za njih je v tem okviru možna rešitev, da si, ali pa da jim, ustvarijo fantazmo Drugega. Takoj, ko se s pomočjo ideoloških mehanizmov vzpostavi podoba Drugega, v veliki meri odpade grozeča potreba po vzpostavitvi horizontalne razredne solidarnosti (politike emancipacije), utrdi se kontinuum vertikalne hierarhije in ob »grožnji « Drugega tudi patološka navezanost na nadrejene in raznovrstne mitologizirane psevdosolidarnosti (npr. nacionalizem). Horizontalno solidarnost, ki pomeni konstitucijo ljudstva ali multitude, zamenja vertikalno sledništvo (Gefolgschaft) črede. Ljudstvo se preobrazi v drhal.

Liberalno dojemanje kopice individuumov v svobodnem prerivanju na kontinuumu hierarhije na dnu vzpostavi mejo med človeškim in animalnim svetom, kjer rasizem pomeni izrivanje »druge vrste « v svet animalnega. ${ }^{8}$ Seveda pa so tisti zgoraj tam po božji volji oziroma ker jih je med $1 \%$ - povedano bolj sekularno - pripeljala pravična nevidna roka trga.

Rasizem kot konstrukt Drugega, ki je potisnjen na ono stran civilizacije, nima zgolj ideoloških učinkov sproščanja frustracij, ki jih prinaša negotovost permanentne evalvacije in razmeščanja na lestvici ne/uspeha in ne/moči, ampak tudi realne ekonomske učinke, saj določene populacije ne konkurirajo več na »prostem« trgu dela, ampak je njihov status prej podoben delovnim živalim. ${ }^{9}$

Ideološka raba rasizma je danes v ospredju zaradi begunske in migracijske »krize«, ki s fašistično retoriko uveljavlja skrajne desničarske režime in politična gibanja, najprej na postsocialističnem vzhodu (od Poljske pa navzdol) in kmalu tudi drugod, v Britaniji, Franciji, Nemčiji, na Nizozemskem itn. Preden je Donald Trump v predvolilno predsedniško kampanjo vpeljal skrajen rasistični in seksistični diskurz, smo imeli v Evropi na oblasti že kar nekaj »trampčkov«. Rasistično in ksenofobno nasilje, požigi, pretepi in uboji,

7 Ko v proučevanem krdelu alfa samci poginejo, ker so imeli privilegiran dostop do okuženega mesa s smetišča, preostali pavijani spremenijo svojo kulturo v bolj sodelovalno in nehierarhično. Sapolsky tedaj prestopi naravoslovne omejitve in nas vpraša, kako to, da se mi ne naučimo iz svoje zgodovine nečesa, kar so zmogli pavijani v pol leta.

8 Izrivanje iz sveta »kulture« v svet »narave«, ki zahteva pokroviteljstvo in gospostvo, se ne izvaja zgolj nad koloniziranimi ljudstvi, temveč tudi nad ženskami, ki jih določa njihovo domnevno primarno »naravno poslanstvo«. Če je rasizem nujna strukturna posledica potrebe po Drugem, pa je tej strukturi, ki se kristalizira na hierarhičnem kontinuumu, imanenten tudi patriarhat in nasploh ambivalenten pogled na ženske, ki so v

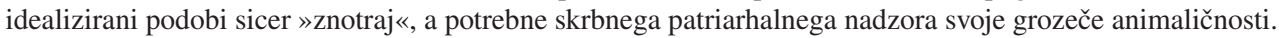

9 Spomnimo se samo na afero izkoriščanja bosanskih delavcev na gradbiščih v Sloveniji. Takšnih primerov je v »razviti« Evropi polno, kjer v nemogočih razmerah dela milijone migrantov, ki za države ne obstajajo, ker so nedokumentirani oziroma »ilegalni«. 
pa tudi napadi na pripadnike levičarskih gibanj, ki temu nasprotujejo, so postali stalnica evropskih poročil, tako da danes glede tega ni razlik med Finsko, Švedsko in Madžarsko ali katerokoli drugo državo. Ekscesna politika je padla na plodna tla ne zaradi tega, ker bi temu bil kriv zgolj populizem oziroma hujskaški politiki, razlogi so globlji in izhajajo iz zgoraj opisane zastavitve hierarhičnega kontinuuma, kjer »zgube« rabijo Drugega na drugi strani meje oziroma prepada.

\section{PREPADNO MIŠLJENJE}

Ne glede na pomembne sprožilce fašizma, kot je gospodarska kriza, ki je izbruhnila leta 2008, in nasploh neuspešno reševanje padajoče profitne stopnje s financializacijo in politiko zategovanja pasu (austerity) slednjega v veliki meri določa prepadno mišljenje (abyssal thinking) (de Sousa Santos, 2014). To pa je, ne glede na politično korektnost povojnega liberalizma, bilo ves čas prisotno in je tlelo kot subalterna zavest. Zato je imela državljanska (civic) vzgoja, kljub velikim vložkom - tudi v bogatih skandinavskih deželah, ki jih danes pretresa ksenofobno nasilje -, zelo omejen učinek. ${ }^{10}$ Razlog je v tem, da pri rasizmu, ksenofobiji, seksizmu, homofobiji itn. ne gre zgolj za predsodke, ki bi jim botrovalo nepoznavanje, temveč za sistemske determinante, ki so imanentne obstoječi različici moderne.

Meja med tekmovalnim prizoriščem »svobodnega sveta«, ki vzpostavi hierarhični kontinuum, na katerem se razvrščajo bolj ali manj ne/uspešni individuumi, in tistim, kar je onkraj dna tega kontinuuma in sega v animalni svet kaosa in nasilja (de Sousa Santos, 2014), je predvsem kolonialna meja. V tem pomenu je rasizem vsakršno izrivanje ljudi in njihovih kultur $\mathrm{v}$ to animalno onostranstvo, ne glede na odtenek njihove polti. Četudi kolonialni rasizem svoj neslavni vrh doseže v zasužnjevanju Neevropejcev, pa je to logiko izločanja in nepripuščanja mogoče zaznati tudi drugod: pri odnosu severa Evrope do juga, zahoda do vzhoda ipd. Ponavljajoči se »antibalkanski« izbruhi nacionalizma in ksenofobije v Sloveniji, ki jih sprožajo vedno isti politiki in njihove politične stranke, temeljijo na enaki izprijeni »argumentaciji«: »južnjaki« so necivilizirani, iracionalni, nevladljivi, animalni, nasilni, umazani in vir okužb. Seveda so bili tudi Slovenci žrtve podobne »argumentacije « svojih severnih in zahodnih »nosilcev civilizacije«. Tako imenovana begunska kriza iz leta 2015/2016 razkriva podobno prepadno mišljenje, ki nas postavi pred jasno nalogo dekolonizacije Evrope in drugih centrov globalno dominirajočega »svobodnega sveta«. Ta svet namreč sproža ali pa se lahkotno vmešava v uničujoče vojne na drugi strani post/kolonialne pregrade, kjer zanj ne veljajo pravila civiliziranega sveta in temeljne človekove pravice. ${ }^{11}$

10 Spomnimo se, kako so tudi v Sloveniji prav v času izbrisa desettisočev ljudi iz evidenc o stalnem bivališču hkrati izvajali propagandno kampanjo »Vsi drugačni - vsi enakopravni«, ali pa da je operativno odgovornost za izbris imela državna sekretarka, ki je bila članica liberalnodemokratske in ne katere od desničarskih strank.

11 Vzemimo za primer arbitrarno internacijo v Gvantanamu, izvensodne poboje teroristov z brezpilotnimi letali in spremljajoče »obstranske « žrtve, oboroževanje skrajnih verskih milic na Bližnjem vzhodu ipd. 
Izoliranim posameznikom, ki se kopičijo predvsem na dnu sodobne hierarhične evalvacijske lestvice, v zadnjih desetletjih grozi še proces globalizacije, ko se materialna produkcija premesti na globalni jug. Tam potreba po množici delovne sile, ob podpori lokalne avtokracije, prispeva k uničevanju gospodarskih (zlasti agrarnih) temeljev, hkrati pa to premeščanje tradicionalne industrije $\mathrm{v} »$ razvitem « svetu pušča presežke delovne populacije. Ti presežki se ne morejo v celoti zaposliti v »kreativnih« industrijah ali pa z ustvarjanjem »bullshit jobs« (Graeber, 2013). Subalterni rasizem in resentiment »zgubarjev« iz razvitega sveta dopolnjuje še kriptorasizem oziroma dozdevno nevtralna tehnokratska »argumentacija ${ }^{12}{ }^{12}$ Globalizacija ${ }^{13}$ in permanentne vojne sprožajo migracijske in begunske eksoduse neverjetnih razsežnosti in tragičnih usod in obenem razkrajajo jasno začrtane, nekoč oddaljene meje med »nami « in »njimi«. Te meje so zdaj pripeljane do našega praga in pomnožene, že itak spodkopane pozicije na hierarhičnem kontinuumu pa postanejo tako še bolj prekarne in kompleksne. Realne in namišljene napetosti in frustracije rabijo le neznatne namišljene ali dejanske povode ter brezskrupulozne politike in medije, da subalterni in prikriti rasizem $v$ trenutku prerasteta $\mathrm{v}$ odkrito politiko sovraštva in nasilja. Pripisati razloge zgolj populističnemu oziroma demagoškemu zapeljevanju množic, ne da bi razumeli formno določitev hierarhičnega kontinuuma, na katerem sloni kapitalizem, in njegovo kolonialno ločnico, ki večji del sveta pahne na raven naravnih in (napol) človeških virov, je pomanjkljivo in ne omogoča učinkovitega zoperstavljanja rasistični, seksistični, homofobni politiki sovraštva in nasilja.

\section{REFORMULACIJA ANTIRASISTIČNEGA IZOBRAŽEVANIA}

Če ugotavljamo, da je današnje izobraževanje neuspešno in nemočno pred rastjo rasizma in drugih politik sovraštva, je treba vzeti v obzir dve izhodišči: (1) izobraževanje je pomemben dejavnik antirasizma, ni pa edini in sam po sebi odločilen; in (2) izobraževanje, ki se slepo prilagaja in služi vladajočemu sistemu, z nekaj antirasističnimi kurikularnimi dodatki ne more doseči želenih ciljev.

Izobraževanje, bodisi kot institucionaliziran podsistem bodisi kot splošna družbena praksa, sobiva in se sooča z diskurzivnim oblakom različnih formalnih in neformalnih akterjev. Tam se prepleta marsikaj: od ulice, domače vzgoje in računalniških videoigric, političnega marketinga, resničnostnih šovov, kulturne industrije, etike potrošništva, virtualnih socialnih omrežij, telenovel, rumenega tiska, patoloških nacionalnih mitologij, pasivne in aktivne državne represije itn. Skratka, na delu imamo ideološki stroj, ki proizvaja tudi

12 Če se subalterni rasizem izraža npr. z zmrdovanjem nad »Kitajčki, ki delajo za skodelico riža«, pa je značilen primer kriptorasizma ideologem družba znanja, ki naj bi na zahodu ustvarjala »dodatno vrednost«, medtem ko je materializacija idej prepuščena delavcem tretjega sveta, ki ne zmorejo doseči naše ravni znanja (sic.). Slednje tudi ekonomistično označujejo kot »ceneno« delovno silo, kar zakrije njihovo izkoriščanje in zatiranje, tako da to dvoje ne prestopi praga naše percepcije in elementarne empatije. $Z$ one strani kolonialnega prepada nas zato upravičeno dojemajo (vsaj) kot nemoralne, medtem ko oni za nas ostajajo nevidni.

13 Čeprav se je družbenega gibanja ob prelomu tisočletij oprijela žurnalistična označba »antiglobalisti«, so ti praviloma zagovarjali zgolj alternativo neoliberalni globalizaciji, npr. globalizacijo pravic in prost pretok ljudi, in ne zgolj kapitala. 
subalterni in kriptorasizem, ki predhodita odprtemu rasizmu in drugim politikam sovraštva, ki lahko pozneje postanejo prevladujoče uradne doktrine. Učinkovit antirasizem bi moral delovati na vseh ravneh tega oblaka in ne zgolj na ravni preprostega pedagoškega imaginarija vplivanja na zavest posameznikov..$^{14}$ Soočanje s politiko sovraštva zahteva široko politično mobilizacijo, za kar pa sodobna družba ni najbolje usposobljena, ker povedano cinično in $\mathrm{v}$ neoliberalnem duhu - družbe ni, ampak obstajajo zgolj izolirani posamezniki, ki svojo politično apatijo zdravijo s sledenjem cikličnemu štiriletnemu političnemu marketingu in še kakšnim vmesnim političnim resničnostnim šovom. Podreditev hierarhičnemu kontinuumu, kjer smo definirani kot agonalni individuumi, ki nismo sposobni horizontalnega, solidarnega oziroma resnično političnega delovanja, ima za posledico, da nas izobraževanje nagovarja kot takšne. To je seveda protislovno: pričakovati od ljudi solidarnost (antirasizem), hkrati pa jim ne odpreti vizije prek sistema, ki jih obsoja na solipsistični egoizem. Ker rasizem ni posledica predsodkov in nepoznavanja in so ti le simptomatska posledica določujočega režima izključevanja, je treba, tako kot je učil in delal Paulo Freire (Freire, 2000), usposabljati tudi za spremembo takšnega sveta. Naivno je zaupati zgolj v sposobnost državno nadziranega šolstva, kjer je država eno od modernih orodij, ki je od 17. stoletja dalje nastajala v sozvočju s hierarhičnim kontinuumom. To ne pomeni, da se tisti, ki smo znotraj tega sistema, ne moremo preusmeriti v družbene prakse odpora, kar pa zahteva radikalno spremembo izobraževalnega horizonta.

Sodobna prevladujoča mehanicistična vulgarna pedagogika izhaja iz določitve »kompetenc $\ll,{ }^{15}$ ugotavljanja deficita in dopolnjevanja kurikularnih sprememb ter postopkov (metodik). Ta shema ne presega sistema, temveč ga zgolj potrjuje, ko subjektov ne dojema kot avtonomne komunikativne akterje, temveč zgolj kot izvajalce v mehanični strukturi. Večkulturno izobraževanje oziroma spoznavanje »drugih « kultur, kot to opredeljujejo različne kurikularne vsebine (npr. pri državljanski vzgoji), je smiselno in učinkovito le, kolikor je uporabno za oblikovanje mestizaje. ${ }^{16}$ Tudi ko govorimo o vključevanju različnih populacij in posameznic ter posameznikov, ki so v emancipacijskem gibanju, ni zadostno govoriti o inkluziji, saj ima ta smisel le, kolikor gre za izboljšanje in spremembo življenjskih okoliščin za vse. Ker gre za kvalitativne spremembe, se mi zdi izraz mestizaje primernejši, ker meri na široko pojmovanje kakovosti življenja in ne zgolj na nekaj, kar je kvantitativno merljivo (dohodek, BDP).

\section{REFLEKSIJSKI KROŽKI KOT POLITIČNO DELOVANJE}

Obstoječi šolski sistem ne more biti edina podlaga političnega delovanja in učitelji ne agitatorji, kar pa ne pomeni, da tam ne moremo imeti prostora intelektualnih eksperimentov

14 Prelaganje naloge antirasizma zgolj na izobraževalne inštitucije, ki se jih potem obtožuje za neuspeh, je krivičen, vendar pogost ideološki manever.

15 Povedano brez ideološkega okrasja: gre za evidentiranje standardov blaga, namenjenega trgu delovne sile.

16 To načelno odprtost in učljivost kultur nacionalisti dojemajo kot grožnjo identiteti, ki pa je seveda fiktivna, kolikor jo dojemamo kot homogeno in statično, saj tudi Prešeren ne bi bil to, kar je, brez intelektualne »odprtosti« in dojemljivosti za nemško in nasploh evropsko romantiko. 
in komunikativne presoje, ki je lahko podlaga vključevanja v emancipacijske procese zunaj inštitucije, pa tudi produktivnih konfliktov navznoter, ${ }^{17}$ kolikor takšna komunikacija in presoja naletita na ovire. Šolski in akademski prostor bi topogledno morala predstavljati priložnost trezne presoje, ki analizira omenjeni diskurzivni oblak in omogoča ustrezno oblikovanje militantnih skupnosti in njihovo delovanje. Refleksijski krožki pa ne bi smeli biti omejeni na inštitucije, ampak bi morali nasploh prispevati k prenovi civilne družbe.

Pred desetletjem sem bil gost gibanja delavcev brez zaposlitve (MTD - Movimiento de trabajadores desocupados) v četrti Solana v Buenos Airesu. Tam so se prebivalci samoorganizirali zaradi dolgotrajne gospodarske in politične krize. Organizirali so javno prehrano, vrtce, produkcijske zadruge, ekološko pridelavo hrane, različne oblike kulturnega življenja, zlasti za mlade, ki so bili drugače izpostavljeni drogam in kriminalu. Med različnimi oblikami samoizobraževanja so imeli tudi refleksijske krožke, na katerih so obravnavali pereča družbena vprašanja in brali teoretska besedila (npr. Nevednega učitelja Jacquesa Rancièra). Sodelovale so ženske in možje različnih starosti, med njimi tudi njihove izpostavljene aktivistke in aktivisti (levi katoličani, marksisti, levi peronisti, anarhisti, skratka, politična mešanica, ki je tvorila gibanje piqueterov). Na razprave so prihajali tudi radikalni študentje in študentke iz centra mesta, a večina udeleženih ni imela prav veliko formalne izobrazbe. Ne glede na to so bile razprave temperamentne in plodne, pri prisotnih ni bilo opaziti posebnih hierarhij. Razprave so snemali in jih pozneje objavili v brošurah, ki so bile prav tako urejene nehierarhično: beseda starejše gospodinje je postala prav tako vidna kot bolj »sofisticiran« diskurz študenta filozofije. Na podoben način so se lotili umetniških projektov: njihovega življenja ni beležil kak znamenit fotograf, ampak jih je ta usposobil in jim omogočil, da so sami dokumentirali svoj vsakdan in objavili knjigo. ${ }^{18}$ Dinamična in kulturno odprta skupnost, ki so jo vzpostavili s svojim avtonomnim neavtoritarnim horizontalnim delovanjem, je ustvarila paralelni svet v faveli, ki je sicer živela v senci steklenih nebotičnikov velemesta. Od tam zgoraj so kmalu dojeli grožnjo, ki jim preži od spodaj.

Če dojamemo antirasizem kot vzpostavljanje horizontalne povezave, solidarnost in rekuperacijo skupnosti, je ta rekonstrukcija družbe evidentno nasprotna procesu tržne individualizacije, ki jo dopolnjuje institucionaliziran paternalizem države. Kompromisne rešitve med tema dvema vrstama socializacije niso možne. Antirasizem ni zidanje mostu prek kolonialnega prepada med našim svetom svobodne konkurence in animalnim onostranstvom, ampak pomeni uničenje celotnega konstrukta.

Čeprav vertikalno socializacijo koncipiramo kot ideologijo (Haug, 2009), se zavedamo, da so ritualne prakse pomemben del vsakršnega in ne zgolj ideološkega ponotranjenja razmerij gospostva in podrejanja. Pojmovati ideologijo zgolj kot napačno zavest, ki predpostavlja »resnico«, je preozko. Tudi Marx pri tem uporabi izraz verkehrte - ideologija je

17 Zunanja administrativna (re)teritorializacija šole bi se morala nevtralizirati z notranjo strokovno težnjo po transgresiji in z dinamiko dialoške pedagogike.

18 Cumbia, fotografías de la cooperativa Sub, Jorge Baudino Educiones, Buenos Aires 2006. 
»preobrnjena«, »previhana« in ne zgolj napačna zavest. V dnevno prakso izobraževanja bodočih učiteljev brazilskega družbenega gibanja kmetov brez zemlje (MST - Movimento dos trabalhadores sem terra ${ }^{19}$ so zavestno vključeni rituali, ki mešajo lokalne magične rituale z levičarsko ikonografijo, kar označujejo za mistiko (Bricman, 2015). ${ }^{20}$ Antirasizem torej ni kurikularna naloga, ki bi morala v nevednost in predsodke zapeljane peljati na pravo pot, temveč kulturno-politična naloga. Antirasizem zadeva osebno in kolektivno omiko, v svoji izobraževalni razsežnosti pa je umeščen v humanistiko in ne v mehanično zapolnjevanje kompetenc $\mathrm{z}$ določenimi vsebinami in metodikami.

\section{OMIKA KOT MESTIZAJE}

Če razumemo moralno osebnost obenem kot politično, se pravi sposobno delovanja z drugimi pri sooblikovanju skupnosti, potem je medij omike nepogrešljiv. Ta omika kot mestizaje je še posebej učinkovita v sodobni urbani kulturi, v undergroundu, deloma pa tudi v komercialnih odtokih npr. hip hop kulture. Prav zaradi tega je razumljivo, zakaj se v zadnjem času študiji humanističnih vsebin izrivajo iz srednjega in višjega izobraževanja in nadomeščajo z različnimi bolj »uporabnimi« tehnikami podjetniškega usposabljanja. Če družbe več ni in komunikacijo zamenja sistem administrativnega (oziroma korporativnega) nadrejanja in podrejanja, potem humanističnega izobraževanja tudi ne rabimo. Izobraževalni sistemi, ki pristopajo k ljudem instrumentalno, kot k objektom (Zadnikar, 2011), ki jim je treba zapolniti pomanjkljivosti v kompetencah, so ustreznica kapitalističnim razmerjem, kjer se človek in koristnost njegovega dela, delovanja in ustvarjalnosti merita zgolj z dobičkonosnostjo.

Sodobni izobraževalni rituali se na pedagoškem področju večinoma opirajo na družboslovne vede, ki so se oblikovale konec 19. in v začetku 20. stoletja. Novonastale vede so naravoslovne postopke poskušale prenesti na obravnavo človeka, njegovih družbenih oblik in kulturnih fenomenov. Ta sprememba se vpisuje v spremembo oblastnega diskurza 19. stoletja, ko se oblast ne potrjuje več z močjo nad človeškim življenjem, temveč prevzame sodobno obliko biopolitike (Foucault, 2015), ki ima za predmet regulacijo populacije (njeno spodbujanje, varovanje, nadzor, upravljanje). Vzgojne in izobraževalne inštitucije imajo najpoprej to biopolitično funkcijo, da s pomočjo družboslovnih diskurzov (ki jih oblasti v ožjem pomenu besede uporabljajo za »strokovne podlage « svojih upravnih postopkov) za svoj predmet proizvedejo predšolskega otroka, šolarja, dijaka in študenta ter jih usmerjajo glede na druge vladajoče diskurze (moralne, politične, religiozne in potrošniške »vrednote«). Humanistična izobrazba v današnjih neoliberalnih razmerah neposredno ne podpira te nove tehnologije oblasti, ker je prek ukvarjanja z narativno podlago človeštva usmerjena k samorefleksiji in ne k upravljanju človeških

19 Družbeno gibanje združuje kmečki proletariat, ki okupira neobdelano zemljo veleposestnikov. Ker mobilizira in samoupravno organizira življenje prek 300.000 družin, je to bržkone največje družbeno gibanje na svetu.

20 Podoben mestizaje majevske simbolike, katolicizma in anarhokomunističnih simbolov na vsakem koraku srečujemo v uporniških zapatističnih skupnostih na jugovzhodu Mehike. 
objektov (branje knjig, pripovedovanje pravljic vs. vzgojne metodike, trg prostočasnih dejavnosti itn.). Vprašanje je, ali na vzgojno-izobraževalnem področju, v duhu danes dodobra razkrojenega razsvetljenskega ideala avtonomne osebnosti (ki po Kantu temelji na sposobnosti samorefleksije), sploh še je prostor za narativno imaginacijo humanistične izobrazbe ali so jo do kraja okupirale obrtne, tehnične, administrativne in marketinške obravnave otrok in staršev.

Pri tem klasičnega humanističnega izobraževanja ne smemo idealizirati. Spomin na klasično buržoazno rabo humanistike nas opozarja, da ta sama na sebi ne oblikuje antirasistične in nasploh solidarne zavesti, saj je bila v preteklosti pogosto orodje nacionalizma in drugih hierarhičnih ideologij. Velja opozorilo Edwarda Saida:

»Nikakor nisem predlagal, da bi predmet opustili, sem pa predlagal, da bi opustili lahkotna enačenja med našo tradicijo in humanistiko. Obstajajo druge tradicije in torej tudi druge humanistike: seveda bi jih nekako lahko upoštevali in vključili kot nekaj, kar je zamajalo nepreverjeno osrednje mesto tega, kar je bilo dejansko skovano kot naše.«(Said, 2005, str. 257)

Saidu (2005, str. 264) »je bistvo humanizma sekularna predstava, da zgodovinski svet ustvarjajo ženske in moški, ne bog, in da ga lahko razumsko dojamemo skladno s principi, ki jih je razvil Giambattista Vico v delu Scienza Nuova, da torej lahko zares razumemo samo to, kar smo ustvarili, z drugimi besedami, stvari lahko (s)poznamo v skladu s tem, kako so bile narejene«. Torej gre za pristop, ki človeka ne rabi instrumentalizirati in objektivirati zunaj komunikativne racionalnosti, tako kot to počne večina sodobnih družbenih ved, katerih telos ni človeška skupnost, ampak postvarela razmerja (dobiček, administriranje, tehnološki procesi).

Narativna imaginacija humanistike je sposobna ustvariti horizontalni mestizaje, zato Said opiše odmik od »suhe« tradicionalne (apolitične) humanistike k sodobnim ženskim, etničnim, gejevskim, kulturnim in postkolonialnim študijam. K temu bi dodali urbano kulturo, ki na zahodu doživi svoj zalet v drugi polovici 20. stoletja in je v temelju večkulturna oziroma čezkulturna. ${ }^{21}$ Ti pristopi nikakor niso politično neangažirani, nevtralni in nekritični.

Prav ta kritični in politični potencial humanistike, ki se zoperstavlja splošni kapitalistični potujitvi, spoznajo elite za nevarnega in zato denuncirajo humanistiko kot »neuporabno«, v smislu: »Rabimo inženirje, menedžerje in ne filozofe.« Ta ideologija hitro zastrupi srca staršev, ki jih bolj kot osebnostna rast lastnih otrok zanima njihova poznejša kariera. Posledično v šolskem sistemu humanistične pristope zamenjujejo različne »sodobne tehnologije poučevanja « oziroma manipulativno usposabljanje za domnevno dobičkonosne veščine (»kompetence«). Zapiranje humanističnih oddelkov tudi na pomembnih

21 Podelitvi Nobelove nagrade za literaturo Bobu Dylanu je sledilo precejšnje nelagodje med elitami in v medijih, ki jim ta kultura grozi, bodisi zaradi neelitnosti bodisi zaradi kozmopolitstva. 
univerzah, ne zgolj v ZDA, ampak tudi v Franciji in drugod, je le vrh tega splošnega procesa neoliberalne revolucije. ${ }^{22}$ Martha Nussbaum $(2012$, I.) ugotavlja:

»Žejni nacionalnega profita, države in njihovi izobraževalni sistemi nepremišljeno opuščajo sposobnosti, ki so potrebne, da ohranijo demokracijo pri življenju. Če se bo ta trend nadaljeval, bodo države po svetu proizvajale generacije uporabnih strojev namesto sposobnih državljanov, ki lahko mislijo sami, kritizirajo tradicijo in razumejo pomen trpljenja in dosežkov drugih oseb. Prihodnost svetovnih demokracij je na preizkušnji.«

Premagovanje rasizma je vsekakor tudi izobraževalni projekt, a je lahko uspešen le, kolikor se zavedamo omejenega dometa izobraževanja v diskurzivnem oblaku, ki ga proizvajajo ideološki aparati. Takšno izobraževanje se mora še kako dobro zavedati narave aparata, $\mathrm{v}$ katerem deluje, in videti prek njega, prav tako kot je solidarnost horizontalno vezno tkivo, ki gre prek sistema, ki nas individualizira in sili, da bi ljudi potiskali na stran Drugega. Zavračanje neoliberalizma na vseh točkah, kjer je ta koloniziral naša življenja, dekolonizacija centrov svetovne nadmoči in vključevanje epistemologije Juga oziroma mestizaje humanistike so dejavne predpostavke konstitucije antirasistične in solidarne kulture. Tu pa ne gre za eshatološko tematiko, temveč za vsakdanja prizadevanja, tako da ne gre za čakanje na neki prihodnji idealni svet, temveč za konkretno emancipacijsko prakso.

\section{LITERATURA}

Bricman, T. (2015). Pedagogika revolucije ali revolucija pedagogike?: primer Nacionalne šole Florestan Fernandes v São Paulu, Brazilija (Magistrsko delo). Filozofska fakulteta Univerze v Ljubljani, Ljubljana.

De Castro, E. V. (2014). Cannibal Methaphysics. Minneapolis: Univocal Publishing.

Foucault, M. (2015). Rojstvo biopolitike - Kurz na Collège de France 1978-1979. Ljubljana: Krtina.

Freire, P. (2000). Pedagogy of the Oppressed. New York in London: Continuum.

Graeber, D. (2013). On the Phenomenon of Bullshit Jobs. Pridobljeno s http://strikemag.org/bullshit-jobs/.

Haug, W. F. (2009). Kritik der Warenästhetik: Gefolgt von Warenästhetik im High-Tech-Kapitalismus.

Frankfurt na Majni: Suhrkamp.

Nussbaum, M. (2012). Not for Profit, Why Democracy Needs the Humanities. Princeton: Princeton University Press.

Said, E. W. (2005). Oblasti povedati resnico. Ljubljana: Založba *cf.

Sapolsky, R. (2008). Stress: Portrait of a Killer. Pridobljeno s http://killerstress.stanford.edu/.

De Sousa Santos, B. (2014). Epistemologies of the South - Justice against Epistemecide. Boulder in London: Paradigm Publishers.

Zadnikar, D. (2011). Avtonomija globalnih odporov in beda pedagogike. Vzgoja in izobraževanje, $42(1 / 2), 24-32$.

22 Neokonzervativizem s svojim poudarjanjem domnevno krščanskih vrednot, družine, patriarhata, patriotizma itn. je nujno ideološko dopolnilo »brezdušnemu« neoliberalizmu in ohranjanju hierarhičnega kontinuuma, kjer je kritični in odprti humanizem ne samo odveč, temveč tudi nevaren. 